\title{
Determination of the power of a convex-plano intraocular lens in situ from the dioptric keratometer reading of its front surface: extension table for the Javal-Schiøtz ophthalmometer
}

\author{
C D BINKHORST, M C COLENBRANDER, AND L H LOONES \\ From Terneuzen, The Netherlands
}

SUMMARY The size of the reflex image of keratometer mires can be used to determine the power of an intraocular lens (IOL) inside the eye (in situ). The dioptric scale reading from the front surface of a convex-plano intraocular lens in cases of unknown power is compared with computed values. The accuracy of the method is demonstrated in a series of patients with known IOL power. Though in our study we have assumed convex-plano lenses are in use, the same procedure can sometimes be applied to lenses of different forms. To interpret scale readings below 30 dioptres and over 60 dioptres we compiled an extension table, suited to the ophthalmometer of Javal-Schiøtz (HaagStreit), making use of low-powered minus and plus auxiliary lenses in front of the tube of the instrument.

Intraocular lens (IOL) power is controlled by the manufacturer to a high degree of accuracy before packing. Simple methods are available to the surgeon to check IOL power on the operating table before implantation. ${ }^{12}$ Determination of the power of an IOL once it is inside the eye (in situ) may therefore seem to be a merely theoretical problem. However, there may be instances in which the determination of the power in situ acquires a practical interest-for example, when there is doubt about the IOL power used and other important data are lacking or are not reliable.

In our study we made use of the size of the reflex image produced by the front surface of a convexplano IOL. Reflex images of the surfaces of an IOL are much clearer than the third and the fourth Purkinje images of the crystalline lens.

We used the ophthalmometer of Javal-Schiøtz (Haag-Streit) with a slightly increased target illumination by stronger bulbs. The instrument is built for the measurement of the reflex image of its mires produced by the surface of the cornea in air. But with the same instrument it is possible to observe the reflex image of the mires produced by the front

Correspondence to C D Binkhorst, MD, Axelsestraat 54, 4537 Al Terneuzen, The Netherlands. surface of an IOL in situ. It should be understood, however, that the reflex image is observed through the magnifying system of cornea and aqueous. Neither the millimetre scale nor the dioptric scale of the instrument can directly be applied to the IOL. However, if we compare the dioptric scale reading from the front surface of a convex-plano IOL in situ with the values computed for variable IOL power in eyes with variable corneas and variable corneal vertex distances, this reading can be used to determine the power of the IOL. This method was presented for the first time at the first meeting of the European Intraocular Implantlens Council in 1982. ${ }^{3}$

\section{Computation of the dioptric scale reading from the front surface of a convex-plano IOL in situ}

Colenbrander ${ }^{4}$ has demonstrated that the regression line for variations of the corneal refraction and the regression line for variations in depth of the anterior segment of the eye are for practical purposes straight lines. Therefore we selected as variables only three values $(38,43$, and 48 dioptres) for the power of the cornea $\left(F_{c}\right)$, three values $(2 \cdot 5,3 \cdot 5$, and $4.5 \mathrm{~mm})$ for the distance (d) between the apex of the cornea and the apex of the IOL, and five values $(10,15,20,25$, 
and 30 dioptres) for the power of the IOL in situ $\left(F_{1}\right)$.

There are thus three variables: $F_{c}, d$, and $F_{1}$. We executed a computation for the standard combination $\left(F_{c}=43 \mathrm{D}, d=3.5 \mathrm{~mm}\right.$, and $\left.F_{1}=20 \mathrm{D}\right)$, and for the combinations of the above mentioned variations of only one variable in turn, combined with the standard values of the other two variables.

For these computations we made use of the principle of the 'equivalent mirror.' This principle states that a spherical surface (in this case the anterior surface of the IOL) seen through an optical system (in this case the cornea) is equivalent to a spherical surface in air, of which the position of the apex and the centre of curvature are the images formed by the cornea of the corresponding real points.

The computation and their results are shown in Appendix 1.

The results enable us to frame the following set of instructions.

Instructions for the determination of a convex-plano IOL in situ (refractive index 1.4917) having a refracting power within the eye between 10 and 30 dioptres

(1) Read with the ophthalmometer the dioptric value for the reflex image from the IOL inside the eye.

(2) Adjust this dioptric value to the corresponding value for the standard eye. This means: $(a)$ if the dioptric power of the cornea is more (less) than $43 \mathrm{D}$, lower (raise) the dioptric value for the IOL by $0.53 \mathrm{D}$ for each dioptre of difference; $(b)$ if the depth of the anterior segment of the eye is more (less) than 3.5 $\mathrm{mm}$, lower (raise) the dioptric value by $2 \cdot 8 \mathrm{D}$ for each $\mathrm{mm}$ of difference.

(3) Use Table 1 to convert the dioptric value in situ, adjusted for the standard eye, into the refracting power of the IOL.

Appendix 2 gives the comparison of the computed and the actual dioptric power of the IOL in a series of 11 patients.

\section{Extension table for the Javal-Schiøtz ophthalmometer (Haag-Streit)}

The Javal-Schiøtz ophthalmometer (Haag-Streit) is calibrated to read the front curvature of the cornea from 30 dioptres to 60 dioptres. However, with the use of the ophthalmometer to determine the apparent curvature of the front surface of an intraocular lens inside the eye, dioptric values under $30 \mathrm{D}$ and over $60 \mathrm{D}$ may be encountered. Moreover, corneal curvatures under $30 \mathrm{D}$ may occur in rare cases of cornea plana. On the other hand corneal curvatures over $60 \mathrm{D}$ occur in cases of advanced keratoconus. Because the ophthalmometer scale
Table 1 Conversion of the dioptric reading with the ophthalmometer from a convex-plano IOL in the standard eye (cornea $43 \mathrm{D}$, anterior segment depth $3.5 \mathrm{~mm}$ ) into the refracting power of the $I O L$ in situ. $I=$ Reading of the ophthalmometer in dioptres. $I I=$ Corresponding power of the IOL in situ, in dioptres.

\begin{tabular}{llllll}
\hline$I$ & $I I$ & $I$ & $I I$ & $I$ & $I I$ \\
\hline 10 & $10 \cdot 1$ & 25 & $16 \cdot 7$ & 40 & $23 \cdot 3$ \\
11 & $10 \cdot 5$ & 26 & $17 \cdot 1$ & 41 & $23 \cdot 7$ \\
12 & $10 \cdot 9$ & 27 & $17 \cdot 5$ & 42 & $24 \cdot 1$ \\
13 & $11 \cdot 4$ & 28 & $18 \cdot 0$ & 43 & $24 \cdot 6$ \\
14 & $11 \cdot 8$ & 29 & $18 \cdot 4$ & 44 & $25 \cdot 0$ \\
15 & $12 \cdot 3$ & 30 & $18 \cdot 9$ & 45 & $25 \cdot 5$ \\
16 & $12 \cdot 7$ & 31 & $19 \cdot 3$ & 46 & $25 \cdot 9$ \\
17 & $13 \cdot 1$ & 32 & $19 \cdot 7$ & 47 & $26 \cdot 4$ \\
18 & $13 \cdot 6$ & 33 & $20 \cdot 2$ & 48 & $26 \cdot 8$ \\
19 & $14 \cdot 0$ & 34 & $20 \cdot 6$ & 49 & $27 \cdot 2$ \\
20 & $14 \cdot 5$ & 35 & $21 \cdot 1$ & 50 & $27 \cdot 7$ \\
21 & $14 \cdot 9$ & 36 & $21 \cdot 5$ & 51 & $28 \cdot 1$ \\
22 & $15 \cdot 3$ & 37 & $21 \cdot 9$ & 52 & $28 \cdot 6$ \\
23 & $15 \cdot 8$ & 38 & $22 \cdot 4$ & 53 & $29 \cdot 0$ \\
24 & $16 \cdot 2$ & 39 & $22 \cdot 8$ & 54 & $29 \cdot 4$ \\
25 & $16 \cdot 7$ & 40 & $23 \cdot 3$ & 55 & $29 \cdot 9$ \\
\hline
\end{tabular}

does not allow the reading of these values, extension of the reading on both sides became necessary. We therefore developed an extension table for the HaagStreit ophthalmometer, using a minus $2.5 \mathrm{D}$, a minus $1.25 \mathrm{D}$, or a plus $1.25 \mathrm{D}$ auxiliary lens in front of the ophthalmometer tube. Stronger lenses cause difficulties with the forward and backward shift of the instrument.

An explanation of the method of computation is given in Appendix 3. The results are given in Table 2.

Table 2 Conversion of scale readings with an auxiliary lens to the true values in dioptres

\begin{tabular}{|c|c|c|c|c|c|}
\hline \multicolumn{2}{|c|}{$\begin{array}{l}\text { With a minus } 2.5 \mathrm{D} \\
\text { auxiliary lens } \\
\text { (conversion factor } \\
0.5138 \text { ) }\end{array}$} & \multicolumn{2}{|c|}{$\begin{array}{l}\text { With a minus } 1 \cdot 25 \mathrm{D} \\
\text { auxiliary lens } \\
\text { (conversion factor } \\
0.7416 \text { ) }\end{array}$} & \multicolumn{2}{|c|}{$\begin{array}{l}\text { With a plus } 1 \cdot 25 \mathrm{D} \\
\text { auxiliary lens } \\
\text { (conversion factor } \\
1 \cdot 2855 \text { ) }\end{array}$} \\
\hline \multicolumn{2}{|c|}{ Reading True value } & \multicolumn{2}{|c|}{ Reading True value } & \multicolumn{2}{|c|}{ Reading True value } \\
\hline 30 & 15.4 & 30 & $22 \cdot 2$ & 45 & $57 \cdot 8$ \\
\hline 31 & 15.9 & 31 & $23 \cdot 0$ & 46 & 59.1 \\
\hline 32 & $16 \cdot 4$ & 32 & $23 \cdot 7$ & 47 & 60.4 \\
\hline 33 & $17 \cdot 0$ & 33 & $24 \cdot 5$ & 48 & $61 \cdot 7$ \\
\hline 34 & $17 \cdot 5$ & 34 & $25 \cdot 2$ & 49 & 63.0 \\
\hline 35 & $18 \cdot 0$ & 35 & $26 \cdot 0$ & 50 & $64 \cdot 3$ \\
\hline 36 & $18 \cdot 5$ & 36 & $26 \cdot 7$ & 51 & $65 \cdot 6$ \\
\hline 37 & $19 \cdot 0$ & 37 & $27 \cdot 4$ & 52 & $66 \cdot 8$ \\
\hline 38 & 19.5 & 38 & $28 \cdot 2$ & 53 & $68 \cdot 1$ \\
\hline 39 & $20 \cdot 0$ & 39 & 28.9 & 54 & 69.4 \\
\hline 40 & $20 \cdot 6$ & 40 & 29.7 & 55 & $70 \cdot 7$ \\
\hline 41 & $21 \cdot 1$ & 41 & 30.4 & 56 & $72 \cdot 0$ \\
\hline 42 & $21 \cdot 6$ & 42 & $31 \cdot 1$ & 57 & $73 \cdot 3$ \\
\hline 43 & $22 \cdot 1$ & 43 & $31 \cdot 9$ & 58 & $74 \cdot 6$ \\
\hline 44 & $22 \cdot 6$ & 44 & $32 \cdot 6$ & 59 & $75 \cdot 8$ \\
\hline 45 & $23 \cdot 1$ & 45 & $33 \cdot 4$ & 60 & $77 \cdot 1$ \\
\hline
\end{tabular}


Table 3 Results of the computations on the various combinations of eye and IOL power

\begin{tabular}{|c|c|c|c|c|c|}
\hline & \multicolumn{3}{|l|}{ Data } & \multicolumn{2}{|c|}{ Results $\left(F_{o}\right)$ Diff } \\
\hline & $F_{c}(D)$ & $d(m m)$ & $F_{l}(D)$ & (D) & (D) \\
\hline $\begin{array}{l}\text { Variation } \\
\text { in } F_{c}\end{array}$ & $\begin{array}{l}38 \\
43 \\
48\end{array}$ & $\begin{array}{l}3 \cdot 5 \\
3 \cdot 5 \\
3 \cdot 5\end{array}$ & $\begin{array}{l}20 \\
20 \\
20\end{array}$ & $\begin{array}{l}35 \cdot 26 \\
32 \cdot 58 \\
29 \cdot 97\end{array}$ & $\begin{array}{l}0.53 \\
0.52\end{array}$ \\
\hline Variation in d & $\begin{array}{l}43 \\
43 \\
43\end{array}$ & $\begin{array}{l}2 \cdot 5 \\
3 \cdot 5 \\
4 \cdot 5\end{array}$ & $\begin{array}{l}20 \\
20 \\
20\end{array}$ & $\begin{array}{l}35 \cdot 47 \\
32 \cdot 58 \\
29 \cdot 81\end{array}$ & $\begin{array}{l}2 \cdot 9 \\
2 \cdot 8\end{array}$ \\
\hline Variation in $F_{1}$ & $\begin{array}{l}43 \\
43 \\
43 \\
43 \\
43\end{array}$ & $\begin{array}{l}3 \cdot 5 \\
3 \cdot 5 \\
3 \cdot 5 \\
3.5 \\
3 \cdot 5\end{array}$ & $\begin{array}{l}10 \\
15 \\
20 \\
25 \\
30\end{array}$ & $\begin{array}{r}9 \cdot 88 \\
21 \cdot 23 \\
32 \cdot 58 \\
43 \cdot 93 \\
55 \cdot 28\end{array}$ & $\begin{array}{l}2 \cdot 27 \\
2 \cdot 27 \\
2 \cdot 27 \\
2 \cdot 27\end{array}$ \\
\hline
\end{tabular}

The last column shows that indeed the differences per unit are nearly constant. The values of $0.53 \mathrm{D}$ per dioptre difference of $F_{c}$ and of 2.8 $D$ per $\mathrm{mm}$ difference of $\mathrm{d}$ are inserted in the instruction.

Results $=$ readings on the ophthalmometer $\left(\mathrm{F}_{\mathrm{o}}\right)$.

Diff. $=$ difference per unit $(\mathrm{D}$ or $\mathrm{mm})$.

Appendix 1. Computation of the dioptric scale reading from the front surface of a convex-plano IOL in situ

Here follows, as an example, the complete computation for the standard combination.

In order to be in accordance with dioptres, distances have to be measured in metres. However, we expressed distances in millimetres so as not to handle extremely small numbers, and in accordance multiplied the refractive indices by 1000 .

The direction of the light rays is from within the eye to outside the eye. Distances behind the cornea are therefore negative.

I. First, we want to know the position of the image $\left(d^{\prime}\right)$ of the apex (d) of the IOL. The formula used is $A+F=A^{\prime}$ or $(1000 \mathrm{n} / \mathrm{d})+\mathrm{F}_{\mathrm{c}}=$ $\left(1000 n^{\prime} / d^{\prime}\right) . n=1.336 ; n^{\prime}=1 ; F_{c}=43 D ; d=-3.5 \mathrm{~mm} .(1336 /-3.5)+$ $43=(1000 /-2 \cdot 952)$. Thus $d^{\prime}=-2 \cdot 952 \mathrm{~mm}$.

II. Secondly, we want to know the radius $\left(r_{1}\right)$ of the front surface of the IOL. The formula is $F_{1}=1000 \Delta n / r_{1} . F_{1}=20 D . \Delta n=n^{\prime}-n=$ $1 \cdot 4917-1 \cdot 336=0 \cdot 1557.20=155 \cdot 7 / 7 \cdot 785$. Thus $r_{1}=7 \cdot 785 \mathrm{~mm}$, or in the computation $-7 \cdot 785$

III. The (real) position of the centre of curvature $\left(c_{1}\right)$ of the anterior surface of the IOL is $c_{1}=d+r_{1}=-3 \cdot 5-7 \cdot 785=-11.285 \mathrm{~mm}$.

IV. Its image $\left(c_{1}{ }^{\prime}\right)$ is found along the same lines as in section $I$ by the equation $\left(1000 n / c_{1}\right)+F_{c}=\left(1000 n^{\prime} / c_{1}{ }^{\prime}\right)$ or $(1336 /-11 \cdot 285)+43=$ $(1000 /-13 \cdot 265)$. Thus $c_{1}=-13.265 \mathrm{~mm}$.

$V$. The radius of the equivalent mirror $\left(r_{c}\right)$ is $-\left(c_{1}{ }^{\prime}-d^{\prime}\right)$ or $13 \cdot 265-2 \cdot 952=10 \cdot 313 \mathrm{~mm}$.

VI. Just as with the cornea this corresponds with a power $F_{c}$. $F_{c}=(1000 \Delta n) / r_{c}=(1336-1000) / 10 \cdot 313=32.58$. Thus $F_{c}=32.58 \mathrm{D}$. This means that, if the ophthalmometer reading is $32.58 \mathrm{D}$, the IOL in the standard eye has a refracting power of 20 dioptres.

The same computations were made for the other combinations. The results are shown in Table 3.

Appendix 2 Comparison of the computed and the actual dioptric power in situ of the IOL in a series of 11 patients

$F_{c}=$ Mean of the highest and the lowest reading (if there is corneal astigmatism) of the power of the cornea.

$d=$ Distance from the apex of the cornea to the apex of the lens.

$F_{0}=$ Reading on the ophthalmometer of the IOL in situ.

Corr. $F_{c}=$ Correction for the variation of $F_{c}$

Corr. $\mathrm{d}=$ Correction for the variation of $\mathrm{d}$.
$F_{\mathrm{s}}=$ Adjusted reading for the standard eye.

$F_{1} \cdot I=$ Corresponding power of the IOL (D).

$F_{1} \cdot \mathrm{II}=$ Actual power of the inserted $\mathrm{IOL}(\mathrm{D})$

\begin{tabular}{|c|c|c|c|c|c|c|c|c|c|c|c|}
\hline $\begin{array}{l}\text { Patient } \\
\text { no. }\end{array}$ & $\begin{array}{l}F_{c} \\
D\end{array}$ & $\begin{array}{l}d \\
m m\end{array}$ & $\begin{array}{l}F_{\prime \prime} \\
D\end{array}$ & & $\begin{array}{l}\text { Corr. } \\
F_{c}\end{array}$ & & $\begin{array}{l}\text { Corr } \\
d\end{array}$ & & $\begin{array}{l}F_{s} \\
D\end{array}$ & $\begin{array}{l}F_{l} I \\
D\end{array}$ & $\begin{array}{l}F_{1} . \\
D\end{array}$ \\
\hline 1 & & & & & 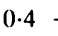 & 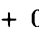 & 0 & & & & \\
\hline 2 & & & & -1 & 0.6 & +( & $0 \cdot 8$ & $=$ & & & \\
\hline 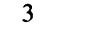 & $45 \cdot 0$ & 3 . & $35 \cdot 1$ & - & $1 \cdot 1$ & + & $0 \cdot 6$ & - & & & \\
\hline 4 & 4 & 3 & 5 & +1 & $0 \cdot 1$ & + & $1 \cdot 4$ & $=$ & & & \\
\hline 5 & & 3 & & - & $0 \cdot 2$ & +( & 0.3 & $=$ & & & \\
\hline 6 & & 3 & & - & 0.8 & + & 0 & $=$ & & & \\
\hline 7 & & & & - & 3 & +( & 0 & 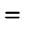 & & $18 \cdot 1$ & \\
\hline 8 & & 3 & & - & $2 \cdot 4$ & + & 0.3 & $=$ & & 1 & \\
\hline 9 & & 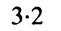 & & - & 0.2 & + & 0.8 & $=$ & & & \\
\hline 10 & 4 & 2. & 3.75 & - & $0 \cdot 0$ & + & $2 \cdot 2$ & - & 35.95 & $21 \cdot 5$ & 19 \\
\hline 1 & $44 \cdot 75$ & $3 \cdot 15$ & $31 \cdot 25$ & - & 1.0 & + & $1 \cdot 0$ & $=$ & 31.25 & $19 \cdot 4$ & 10 \\
\hline
\end{tabular}

Appendix 3 Computations for the extension table for the HaagStreit ophthalmometer

The distance from the plane of focus of the Haag-Streit instrument to the front of the tube for an emmetropic observer and the eyepiece in the emmetropic position is $126 \mathrm{~mm}$. The distance from the focal plane to the auxiliary lens is therefore $125 \mathrm{~mm}$. The divergence of the lightrays coming from the focal plane at this position is exactly 8 dioptres. This is the divergence that the instrument requires at this spot in all circumstances.

A lens of +1.25 dioptres needs a divergence of 9.25 dioptres on entering the lens in order to obtain the divergence of eight dioptres when leaving the lens. The focal plane is then at $1 / 9.25 \mathrm{D}=108 \cdot 11$ mm distance and the shift is $16.89 \mathrm{~mm}$ forward.

In the same way the distance to the focal plane with $a-1.25$ lens will be $1 / 6.75$ dioptres $=148.15 \mathrm{~mm}$ and the shift $23.15 \mathrm{~mm}$ backward.

With the forward shift and backward shift of the instrument in the reading position known, its influence on the size of the reflex images, and thus on the dioptric scale of the ophthalmometer, can be calculated. This influence is twofold: $(a)$ a change of the angle with which the ophthalmometer mires present themselves to the patient's eye; and $(b)$ a change of the observation angle of the reflex images. Both aspects can be expressed in terms of magnification, and thus the final magnification can be calculated.

In an ophthalmometer the coloured objects and the tube are linked together. They go both to and fro. But suppose for a moment that they were not linked. Then it would be possible to move only the objects forwards, which gives a real magnification of the reflex images, and see them in the normal way. Or it would be possible to move only the tube with the plus lens forwards. Then we should have reflex images of normal size, seen enlarged. However, if both the objects and the tube are shifted forwards, there must be a twofold magnification. Each of these magnifications is equal to the proportion of the distances to the focal plane without and with the additional lens. The normal distance from the coloured objects to the focal plane is $168 \mathrm{~mm}$. Thus the magnification with the plus 1.25 D lens is:

for the shift of the coloured objects $M_{1}=\frac{168}{168-16 \cdot 89}=1 \cdot 112$, and for the tube $M_{2}=\frac{125}{125-16 \cdot 89}=\frac{9 \cdot 25}{8}=1 \cdot 156$,

and for both $M_{1} \times M_{2}=1 \cdot 112 \times 1 \cdot 156=1 \cdot 2855$. The magnification with the minus 1.25 dioptre lens is:

for the shift of the coloured objects $M_{3}=\frac{168}{168+23 \cdot 15}=0 \cdot 879$, 
and for the tube $M_{4}=\frac{125}{125+23 \cdot 15}=\frac{6 \cdot 75}{8}=0 \cdot 844$,

and for both $\mathrm{M}_{3} \times \mathrm{M}_{4}=0 \cdot 879 \times 0 \cdot 844=0 \cdot 7416$.

In the same way the magnification with a $-2.5 \mathrm{D}$ lens is $0.7473 \times 0.6875=0.5138$.

These magnification factors are applicable only to the Haag-Streit keratometer and not to other instruments. However, the same method could be applied to other makes, if the relevant dimensions were measured or obtained from the manufacturers. The results of this computation are shown in Table 2.

We acknowledge with thanks critical comments made by Mr A G Bennett on a draft of this paper.

\section{References}

1 Mc Reynolds WL, Snider NL. The quick measurement of intraocular lens power and lens resolution at surgery. Am Intraocular Implant Soc J 1978; 4: 15.

2 Miller D, Manning W, Miller R, West W, Ullen R, Stenowski J. Intraocular lens power check. Am J Ophthamol 1981; 91: 462-4.

3 Loones LH. Intraocular lens power 'in situ.' First meeting of the European Intraocular Implantlens Council, 30 Sept-2 Oct 1982, The Hague, Netherlands.

4 Colenbrander MC. Calculation of the power of an iris clip lens for distant vision. Br J Ophthalmol 1973; 57: 735-40.

Accepted for publication 31 July 1986. 